\title{
Potentiation of the anticoagulant effect of warfarin
}

\author{
DA Fitzmaurice, JA Murray
}

A 63-year-old woman with longstanding rheumatoid arthritis was receiving warfarin therapy for an aortic valve replacement. The dose of warfarin was monitored via a hospital anticoagulation clinic and remained stable at 4-4.5 mg per day with no significant bleeding or thrombotic episodes. In September 1993 the patient began attending a general-practice-based anticoagulation clinic. On 28 January 1994, her International Normalised Ratio (INR) was 9.6 (BSH reference range $=3-4.5$ ). She was taking $4 \mathrm{mg}$ of warfarin a day at this point. Following discussion with the local Haematology department, warfarin was stopped and arrangements made through her general practitioner to recheck the INR the next day. On this occasion her INR was 12.0. Clinically, she had developed some contact bleeding from the gums and some spontaneous bruising around the groin. In consultation with the Haematology department, the patient was advised to attend hospital for vitamin $\mathrm{K}$ administration but this was declined. It was therefore necessary to monitor the patient closely at home. She was seen in hospital on 1 February 1994 when her INR was 4.0. Her regular medication at this time was penicillamine $250 \mathrm{mg} / \mathrm{day}$, naproxen $500 \mathrm{mg}$ bid and ferrous sulphate $200 \mathrm{mg}$ tid. She had been given Co-Dydramol (dihydrocodeine $10 \mathrm{mg}$ and paracetamol $500 \mathrm{mg}$ ) on 24 January 1994 by her general practitioner, for general aches and pains. There was no clinical evidence of gastrointestinal bleeding. She had taken four tablets of Co-Dydramol for seven days, a total of 28 tablets, equal to $14 \mathrm{~g}$ of paracetamol.

On 7 February 1994, her INR was 5.4 despite receiving no warfarin for the previous 10 days. The haemoglobin level was $6.9 \mathrm{~g} / \mathrm{dl}$ and her platelet count $649 \times 10^{9} / 1$, in keeping with recent blood loss. The following day her INR was 2.6 with haemoglobin $7.2 \mathrm{~g} / \mathrm{dl}$ and warfarin was restarted, cautiously, at a dose of $3 \mathrm{mg} /$ day.

On 23 February 1994, the patient was prescribed Tylex (codeine phosphate $30 \mathrm{mg}$ and paracetamol $500 \mathrm{mg}$ ) for joint pains. On 1 March 1994 her INR was checked at the hospital and was 8.5. She had taken three Tylex tablets a day for eight days, a total of 24 tablets, equal to a total paracetamol dose of $14 \mathrm{~g}$. Warfarin was again stopped. On 7 March 1994 her INR was restarted at a dose of $3 \mathrm{mg} / \mathrm{day}$. The blood results are summarised in figure 1. On 13 April 1994 the results were INR=2.7, haemoglobin $11.0 \mathrm{~g} / \mathrm{dl}$ and platelets $444 \times 10^{9} / 1$.

Department of
General Practice,
Medical School,
University of
Birmingham,
Birmingham
B15 2TT, UK
DA Fitzmaurice

Department of Haematology, Selly Oak Hospital, Birmingham, UK JA Murray

Accepted 29 March 1996

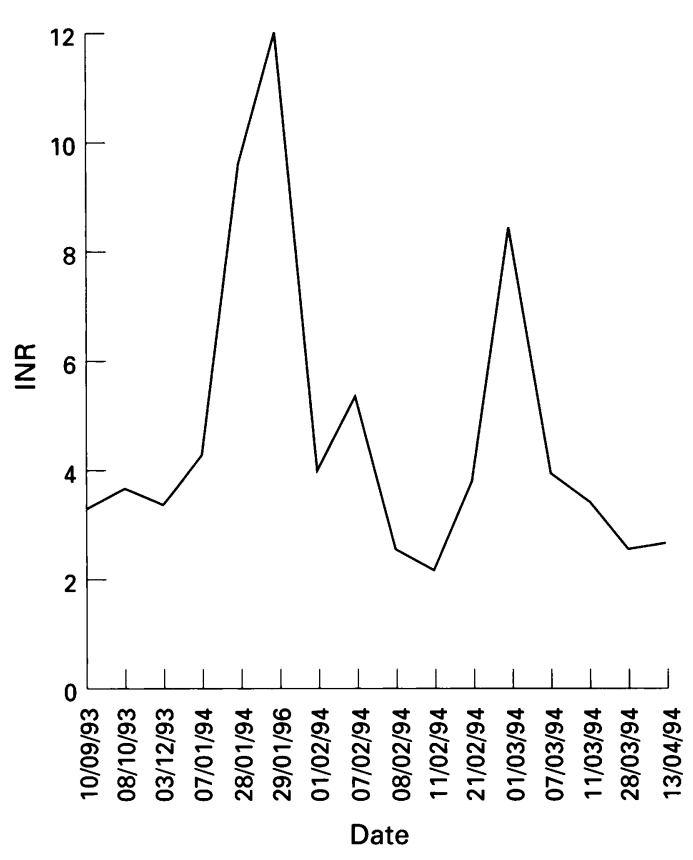

Question

What is the cause of this patient's aberrant INRs?

Figure 1 
Answer

A retrospective diagnosis of paracetamol interaction was made to explain the derangement of this woman's anticoagulant control. On both occasions that her INR was raised, she had taken paracetamol-containing compounds for several days previously. After one year of follow-up, there have been no repeats of these episodes, and the patient has been made aware that she must not take paracetamol-containing compounds again.

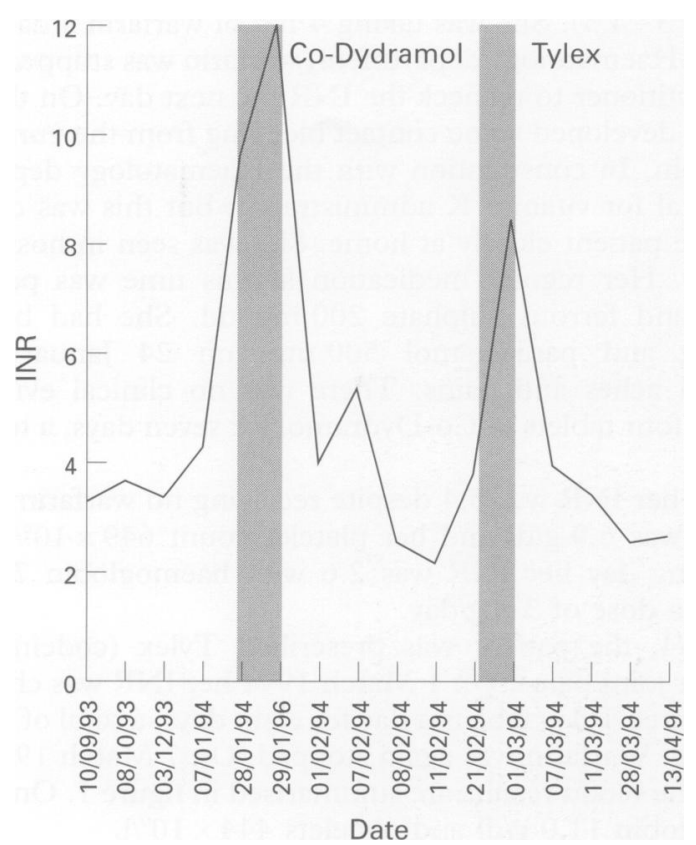

Figure 2

1 Gilman AG, Rall TW, Nies AS, Taylor P, eds. Goodman and Gilman's The pharmacological basis of therapeutics, 8th edn. New York: Macmillan, 1990.

2 Buckley NA, Dawson AH. Drug interactions with warfarin. Med f A Aust 1992; 157: 479-83.

The British Medical Association and the Royal Pharmaceutical Society. British National Formulary 1993; 25: 509.

4 Rubin RN, Mentzer RL, Budzynski AZ. Potentiation of oral anticoagulant therapy by acetaminophen (abstract). Clin Res 1984; 32: 698A.

\section{Comment}

It is well known that paracetamol can interact with warfarin, although this has usually been after long-term usage of paracetamol. ${ }^{1,2}$ The British National Formulary states that warfarin's "anticoagulant effect is possibly also enhanced by ... prolonged use of paracetamol". ${ }^{3}$ Indeed, paracetamol and compounds containing it are the analgesics of choice in patients receiving warfarin. One study has shown that paracetamol given at a dose of $4 \mathrm{~g}$ per day for two weeks can cause a prolongation of prothrombin time ratios of greater than $20 \%{ }^{4}$ There has been one previous case report of derangement of oral anticoagulant control closely associated with consumption of a paracetamol product. ${ }^{5}$ This case highlights the need to be wary of prescribing paracetamol indiscriminately in such cases and the need to be aware of the potential dangers of even short courses of analgesia for patients receiving warfarin, particularly in view of the increasing numbers of patients receiving warfarin. ${ }^{6,7}$ Indeed the severe derangement of this patient's INR and clinical signs of haemorrhage may have resulted in a more severe, possibly fatal clinical outcome without the close attention of both primary and secondary care teams. It would be interesting to know the number of patients attending anticoagulation clinics with high INRs who admit to taking paracetamol in the days previously.

\section{Final diagnosis}

Enhanced anticoagulation caused by interaction of warfarin and paracetamol.

Keywords: anticoagulation, paracetamol, warfarin

5 Bartle WR, Blakely JA. Potentiation of warfarin anticoagulation by acetaminophen (letter). $\mathscr{F} A M A$ 1991; 265: 1260

6 Sweeney KG, Pereira-Gray D, Steele R, Evans P. Use of warfarin in non-rheumatic atrial fibrillation: a commentary from general practice. $B \mathcal{F}$ Gen Pract 1995; 45: 153-8.

7 Lowe GDO. Anti-thrombotic treatment and atrial fibrillation (editorial). $B M F$ 1992; 305: $1445-6$. 